\title{
THE SEASONALITY OF CONSUMER PRICES
}

Michael F. Bryan

Stephen G. Cecchetti

Working Paper No. 5173

\section{NATIONAL BUREAU OF ECONOMIC RESEARCH 1050 Massachusetts Avenue \\ Cambridge, MA 02138 \\ July 1995}

We gratefully acknowledge the comments of James Buszuwski, Claire Gallagher, Jagadeesh Gokhale, Joseph Haubrich, Jeffrey Miron, and Peter Rupert on an earlier version of this paper. This paper is part of NBER's research program in Monetary Economics. Any opinions expressed are those of the authors and not those of the National Bureau of Economic Research.

() 1995 by Michael F. Bryan and Stephen G. Cecchetti. All rights reserved. Short sections of text, not to exceed two paragraphs, may be quoted without explicit permission provided that full credit, including $(\odot)$ notice, is given to the source. 


\title{
THE SEASONALITY OF \\ CONSUMER PRICES
}

\begin{abstract}
In this paper, we reevaluate the evidence of seasonality in prices which we find to be substantially greater than previous research has indicated. That is, seasonal price movements have become more prominent in the relatively stable inflation environment that has prevailed since 1982.

One main conclusion is drawn from this analysis: The amount of seasonality in prices differs greatly by item, making it difficult to generalize about seasonal price movements. A casual reading fails to reveal an easily identifiable origin of the seasonal variation of prices. That is, seasonality in consumer prices is predominantly idiosyncratic in nature, a result that contrasts with studies demonstrating a common seasonal cycle in real economic variables.

This finding has an important practical implication: Given the selective, disaggregated approach taken by the Bureau of Labor Statistics to adjust data seasonally, the existence of idiosyncratic seasonality increases the likelihood of allowing noise in the aggregate CPI at a seasonal frequency. This argues in favor of seasonally adjusting the index after aggregation.
\end{abstract}

Michael F. Bryan

Research Department

Federal Reserve Bank of Cleveland

Cleveland, OH 44101
Stephen G. Cecchetti

Department of Economics

The Ohio State University

Columbus, $\mathrm{OH} 43210$

and NBER 


\section{The Seasonality of Consumer Prices \\ Michael F. Bryan and Stephen G. Cecchetti}

\section{Introduction}

Early in 1993, the Consumer Price Index (CPI) reversed course and increased at an annualized rate of roughly $4-1 / 3$ percent--about $1-1 / 2$ percentage points above its average growth rate during the previous six-month period. The prospect of rising inflation sent shock waves through capital markets and attracted the attention of monetary policymakers. The minutes of the Federal Open Market Committee (FOMC) meeting of May 18, 1993 document a commitment to shift the stance of monetary policy if the inflation statistics continued their ascent:

"In the view of a majority of the members, wage and price developments over recent months were sufficiently worrisome to warrant positioning policy for a move toward restraint should signs of intensifying inflation continue to multiply."

But in the months immediately following the FOMC's "asymmetric directive," the growth rate of the CPI moderated sharply, averaging less than 2-1/2 percent per annum in the final six months of 1993 . For the year as a whole, the CPI rose only about $2-3 / 4$ percent, about 1/4 percentage point below 1992's rate.

A popular interpretation of these events is that the inflationary scare of 1993 was a result of "seasonal" price increases that were not part of a more persistent inflationary process. In fact, several studies have identified a pattern of large price increases during the first several months of every year followed by a more moderate inflation performance over the balance of the year. ${ }^{1}$ Indeed, prior to this recent experience, economists commonly held that prices contained little seasonal variation.

These observations raise an important question. Has the seasonality in prices changed substantially over the past quarter century? Perhaps seasonal variability was obscured by a dominant cyclical variability in prices over much of the post-WWII period.

\footnotetext{
${ }^{1}$ See, for example, Biehl and Judd (1993).
} 
We do, in fact, find that seasonal price movements have become more prominent in the relatively stable inflation environment that has prevailed since 1982. Furthermore, we find that a substantial share of price seasonality is idiosyncratic in nature, which implies that seasonal patterns in individual price series are partially negated in the process of aggregation.

Figure 1 shows monthly movements for the CPI without seasonal adjustment. Though monthly consumer prices are certainly volatile, there is little obvious seasonal movement in the data. However, prices of most components display a distinct seasonal pattern, and for some, such as women's apparel (figure 2), the seasonal pattern is a dominant feature of the data.

In this paper, we reevaluate the evidence of seasonality in consumer prices in light of the relatively stable inflation seen in the U.S. during the past 10 years. In Section I, we describe and catalog deterministic seasonality in individual consumer prices. Section II considers seasonality in aggregate prices and the procedure used by the Bureau of Labor Statistics (BLS) for adjusting individual price data to eliminate seasonal variation. We show that this procedure allows idiosyncratic noise to become incorporated into the price data. We consider the use of a limited influence-estimator, the median CPI as a method of reducing this seasonal noise. ${ }^{2}$ We then briefly describe the case of stochastic seasonality in consumer prices in section III, before concluding in section IV.

\section{The Deterministic Seasonality of Prices}

Miron (1990) identifies broad classifications of seasonal variation for a variable $x_{t}$, the most common being deterministic seasonality, specified as

\footnotetext{
${ }^{2}$ See also Bryan and Cecchetti (1994).
} 


$$
x_{t}=\sum_{s=1}^{S} \alpha_{s} d_{t}^{s}+\varepsilon_{t},
$$

where $d_{t}^{s}$ is a dummy for season $s\left(d_{t}^{s}=1\right.$ in season $s$ of period $t, 0$ otherwise), $\alpha_{s}$ is the mean of $x_{t}$ in season $s, S$ is the number of seasons per year (four for quarterly data and 12 for monthly data), and $\varepsilon_{f}$ is a stationary stochastic process. ${ }^{3}$

Unlike data on real output and nominal money--variables that exhibit substantial deterministic seasonal variation--it is curious to note the absence of a deterministic seasonal pattern in aggregate prices. For example, Barsky and Miron (1989) find that seasonal dummies explain nearly 88 percent of the quarterly variation in U.S. real GDP, more than 92 percent of real final sales, and more than 50 percent of the nominal money stock during the postwar period. Beaulieu and Miron (1990) obtain similar results at a monthly frequency for retail sales, industrial production, and money growth for a broad cross-section of countries.

However, seasonal variation has accounted for only a small share of the variation in aggregate prices in the postwar period (for example, less than 4 percent of the monthly variation in the $\mathrm{CPI}$ ). Perhaps exogenous seasonal increases in aggregate supply fortuitously coincide with increases in seasonal demand, resulting in the substantial seasonality of real spending and output while virtually eliminating the seasonal behavior of prices. This explanation has been dismissed as implausible by Barsky and Miron (1989) and Mankiw and Miron (1990). ${ }^{4}$ Altematively, it may be that aggregate supply is

\footnotetext{
${ }^{3}$ Throughout the paper, we examine seasonality in the log difference of prices. In contrast, the BLS applies a two-sided ARIMA X-11 filter to the level of prices that includes both past and future data. In limited instances where a trend shift in the data is suspected, the BLS seasonally adjusts using intervention analysis (see Buszuwski and Scott [1988]). We chose our method for two reasons: First, since our major interest is inflation, our goal is to seasonally adjust the growth rate of prices, not their levels. Second, we wish to model seasonality as either a deterministic or a simple stochastic process, in order to preserve the timing patterns in the data.

4 This explanation may not be as implausible as it initially seems. We find substantially more seasonality in energy prices after the collapse of OPEC price controls. It may well have been that OPEC price targets, which were managed by production quotas, operated at a seasonal frequency to maintain a constant price of
} 
perfectly elastic. By extension, then, interest-rate targeting policies that do not adjust for fluctuations in the real rate of interest at a seasonal frequency may have real effects that are manifested in exaggerated seasonal output and employment fluctuations (Mankiw and Miron [1990]).

But the observed lack of seasonality in prices has been influenced by the predominant cyclical pattern in inflation during the 1970s and early 1980 s, a pattern that has since been dramatically reduced. And as U.S. inflation has settled into a more stable pattern, seasonal variation has become a relatively more important and more obvious source of monthly price fluctuations. That is, there is certainly less appearance of price stickiness at a seasonal frequency since 1982 .

We use equation 1 to estimate the deterministic seasonal pattern in the monthly CPI over the 1967 to 1993 period and over two subperiods: 1967 to 1981 , and 1982 to 1993 (table 1). For the full period, we find that deterministic seasonality accounts for about 7 percent of the monthly variation in the CPI--similar to the results found by Beaulieu and Miron (1990). In the earlier, volatile inflation subperiod, deterministic seasonality represents about 3 percent of the monthly variation in consumer prices. Since 1982 , however, seasonality accounts for approximately 32 percent of the monthly price movement.

The amount of deterministic seasonality in prices over the 1982 to 1993 period, as measured by the seasonal variance, $\sum_{s=1}^{S}\left(\alpha_{s}{ }^{2}\right)$, differs greatly by item, making it difficult to generalize about seasonal price movements from the 36 consumer items considered here (table 2). For example, the largest seasonal variation in prices occurs in women's apparel (last row), where seasonal fluctuations also represent 82 percent of the total price variation. At the other extreme, food away from home (first row) exhibits a very small

oil. This accentuated seasonal behavior in energy prices may be an important seasonal cost fluctuation for a broad range of commodities in the post-1981 period. 
amount of seasonal variation, which accounts for only about 9 percent of the total price variation in this category.

In some cases, seasonal variation is relatively large, yet still amounts to a small share of the total variation in the individual price series. For example, fuel oil and motor fuel prices each rank high in terms of deterministic seasonal variation, but in both cases such seasonality accounts for only 18 percent of their total price variation. However, while the seasonal variation in medical care services prices is rather small, seasonality contributed to a relatively high proportion of the category's total price variation (57 percent).

A casual reading of the seasonal patterns fails to reveal an easily identifiable origin of the seasonal variation of prices (table 3). Supply fluctuations may explain much of the seasonal behavior in food prices. Specifically, cereal and fruit prices show repeating price declines in the fall, when harvests are generally great, but large positive seasonals in January, when harvests are small. Public transportation prices show a single, large positive seasonal variation in January, and natural gas and electricity prices are generally adjusted upward in early summer (May and June), perhaps a reflection of their regulated environment.

A large share of the price movements, however, is harder to ascribe to obvious patterns in the weather or the timing of holidays. For example, private education costs exhibit a single large seasonal increase in September, the beginning of the school year, which is offset by generally small and negative seasonals over the remaining 11 calendar months, and prices of books and supplies show large positive seasonal adjustments in September and January, coinciding with the start of each school term. New car models and their attendant price adjustments are generally introduced in the fall and, in fact, new car price seasonals are positive and large in the fourth quarter of the year. Shelter prices post large positive seasonal adjustments in July and August, when household migrations are prominent. And apparel prices show pronounced seasonal price fluctuations that 
coincide with the fashion seasons--large positive adjustments in March/April and September/October, and large negative adjustments during "off-season" periods.

In general, though, there is little commonality in seasonal price movements -- the aggregate CPI exhibits small seasonal variation relative to the seasonals in individual component prices; only food away from home prices demonstrated less seasonal movement than did the aggregate CPI between 1982 and 1993.5 In no month was there a statistically significant deterministic seasonal for a majority of prices (table 3 ). The most common, statistically significant seasonal price variations occur in December, when 15 of the 36 components had significant, negative seasonals, against only two significant, positive seasonals. In January, 12 statistically significant, positive seasonals were detected against only four significant, negative seasonals. Moreover, the items that showed negative seasonal price adjustments during the final two months of the year were generally not the same items that tended to rise in price during the first few months of the following year.

The proportion of the monthly aggregate price variation accounted for by seasonality was similar to that of a large number of its components, which directly implies that the unconditional variation in the CPI is also quite small relative to its components. That is, individual goods prices have negative unconditional and seasonal covariances. These results contrast with a number of recent observations on the seasonality of industrial production, shipments, retail sales, and other real magnitudes as documented by Barsky and Miron (1989), Beaulieu and Miron (1990), and Miron (1990). Those variables show a positive correlation in seasonality across sectors and countries, parallel to the comovement in data that is generally presumed to characterize the business cycle.

We can examine the idiosyncratic nature of seasonal price movements directly using the linear decomposition

\footnotetext{
${ }^{5}$ The aggregate CPI used in this study has been constructed using the 36 components and applying 1985
} weights, such as in Bryan and Cecchetti (1994). 


$$
p_{i t}=P_{i}^{a}+S_{t}+s_{i t}+\varepsilon_{i t} \text {, }
$$

where $P_{t}^{a}$ is the average seasonally adjusted price change, $S_{t}$ is the average seasonal price movement, and $s_{i t}$ and $\varepsilon_{i t}$ are mean zero, idiosyncratic seasonality and noise, respectively. That is, aggregate seasonally unadjusted price movements can be defined as

$$
P_{t}^{u}=\sum w_{i} p_{i t}=P_{i}^{a}+S_{i}
$$

where the $w_{i}$ 's are base-period weights that sum to unity over all goods $n$. We can estimate $S_{t}$ directly in the aggregate unadjusted index and subtract it from the deterministic seasonal in the individual components to obtain an estimate of the idiosyncratic seasonals. Table 4 reports the ratio of the idiosyncratic seasonality to the common seasonal variance for each of the 36 components, $\left(\operatorname{var}\left[s_{i t},\right] / \operatorname{var}\left[S_{t}\right]\right)$. In only two of the 36 cases--auto repair and food away from home--was the common price seasonal variance larger than the idiosyncratic seasonal variance. In half of the cases, we find that the idiosyncratic seasonality has more than five times the variance of the common seasonal.

Our finding that deterministic seasonality in prices is largely idiosyncratic in nature may be one reason why studies that have used aggregate price statistics have tended to dismiss the amount of seasonality in price movement. Further, the idiosyncratic tendencies of seasonal price movements have important ramifications for the adjustment of such data.

\section{Aggregate Deterministic Seasonality}

The BLS seasonally adjusts the CPI by first filtering the disaggregated components, then aggregating upward to arrive at the seasonally adjusted price index. 
Seasonal adjustment at the component level allows the BLS to capture the wide range of seasonal patterns that exist in the price data. Moreover, seasonally adjusting the index in this way assures that seasonally adjusted subindexes will aggregate to the seasonally adjusted aggregate index. However, not all components are adjusted, as they must first pass certain statistical criteria; otherwise, they are introduced into the "seasonally adjusted" aggregate index on an unadjusted basis. ${ }^{6}$

Because of the BLS's selective approach to seasonal adjustment, 26 of the $60 \mathrm{CPI}$ subindexes (roughly 20 percent of the weighted index) were left seasonally unadjusted prior to January 1994. Yet, because not all of the components were seasonally adjusted, the BLS may have inadvertently introduced a seasonal pattern into the aggregate price series by eliminating only large seasonal price fluctuations, while allowing the small, offsetting seasonal price adjustments to pass into the index unadjusted. The net result may have been a residual seasonal variation in the price data that became conspicuous when the cyclical variation in prices subsided.

Indeed, over the 1982-1993 subperiod, deterministic seasonality can be detected in the seasonally adjusted CPI (table 5). Specifically, seasonally adjusted consumer prices tended to rise about 2 percentage points (annualized), or about 50 percent more, during January and tended to decline by a cumulatively similar amount during November and December. Such seasonality accounts for more than 10 percent of the variation in the seasonally adjusted CPI over the period.

In an effort to reduce the amount of deterministic seasonality in aggregate consumer prices, the BLS broadened its seasonal adjustment procedure in 1994 to allow the seasonal adjustment of a price series, even if it fails to meet the statistical criteria, if the

\footnotetext{
${ }^{6}$ Specifically, the BLS seasonally adjusts a series if seasonality is demonstrated by an F statistic greater than 7 . While this may seem an unusually rigorous criteria (the unconditional probability of which is roughly $10^{-6}$ ), the BLS notes that the F statistic is biased in autocorrelated data such as this. The BLS further notes that this criterion is commonly used by other statistical organizations, such as Statistics Canada.
} 
index at the next higher level of aggregation meets the criteria for seasonal adjustment. As a result of the new procedure, only 10 of the 60 major subindexes, or about 5 percent of the weighted CPI, were unadjusted in the seasonally adjusted CPI in 1994. This procedural change reduced but did not eliminate the residual, deterministic seasonality in the adjusted CPI. While no single month reveals a statistically significant seasonal at the 5 percent level of significance, Wald tests of the joint significance of the deterministic seasonals show seasonality at the 99 percent confidence level. Moreover, deterministic seasonality still accounts for slightly more than 5 percent of the variation in the seasonally adjusted CPI using the new BLS procedures.

Bryan and Cecchetti (1994) demonstrate how the median in the cross section of consumer price changes reduces idiosyncratic noise in individual prices and improves the inflation signal in the aggregate price change statistic. ${ }^{7}$ Here, we consider residual seasonality in the aggregate price index as a special case of idiosyncratic noise. We test for the existence of deterministic seasonality in the weighted median price change calculated from a cross section of seasonally adjusted data from 36 inclusive components in the CPI. We then compare the results to those of the CPI, similarly constructed (table 6).

Over the full sample, deterministic seasonality was found in the seasonally adjusted CPI at more than a 99.0 percent confidence level, but at only a 82.6 percent level of confidence for the seasonally adjusted median CPI. However, in the post-1982 subperiod, deterministic seasonality can be observed in both the CPI and the median CPI at the 99 percent confidence level.

We tentatively conclude that, due to the predominantly idiosyncratic nature of the deterministic seasonality we observe in consumer price data, the median price change

7 That paper shows how idiosyncratic price disturbances that are manifest as an asymmetric distribution of price changes can be reduced by limited-influence estimators. In that class of estimators, the median has the highest correlation with past money growth and improves CPI forecasts. 
estimate may reduce the influence of such seasonal noise in the aggregate monthly price statistic. These results also have implications for the seasonal adjustment procedures currently employed by the BLS. By seasonally adjusting the data selectively prior to constructing the seasonally adjusted index, the BLS risks inadvertently introducing idiosyncratic noise into the aggregate index at a seasonal frequency. This potential problem could be addressed by seasonally adjusting the index after aggregation. ${ }^{8}$

\section{The Case of Stochastic Seasonality}

As Miron (1990) notes, stochastic seasonality is not qualitatively different or logically separable from stochastic variation at a nonseasonal frequency. ${ }^{9}$ Nevertheless, we consider seasonality of the form

$$
x_{t}=\varepsilon_{t}+\theta \varepsilon_{t-S}
$$

Seasonality of this type might occur when there is a strong seasonal price pattern with large adjustment costs. This might generate intermittent price changes at a seasonal frequency that persist over a period of a few years. An example might be adjustments to school tuition that occur in the fall and are spread out over several school years. Another potential source of stochastic seasonality is when the seasonal cycle and the business cycle interact, such that degree of seasonality depends upon the irregular stage of the business cycle. Such interactions have been demonstrated by Cecchetti, Kashyap, and Wilcox (1994).

\footnotetext{
${ }^{8}$ Obviously, the direct seasonal adjustment of the aggregate index means that an aggregation of the seasonally adjusted component series is unlikely to exactly match the aggregate index, creating the potential for "aggregation anomalies." See Buszuwski and Gallagher (1995).

${ }^{9} \mathrm{~A}$ third source of seasonal variation, the seasonal unit root, commonly specified as $x_{t}=x_{t-s}+\varepsilon_{t}$, was not considered here and has little apparent standing in the theory or evidence of seasonal processes. An example of a seasonal unit root is a calendar effect, such as the number of "paydays" varying irregularly from month to month depending on the rotation of the seven-day week around the calendar.
} 
We test for the existence of stochastic seasonality both independently and jointly with deterministic seasonality for the unadjusted CPI. In no case, and in neither of the two subperiods, were we able to identify a stochastic seasonal process in the aggregate index. However, several individual components exhibit stochastic seasonal variation at the 95 percent confidence level and a few at the 99 percent level (table 7), including educational services, books and supplies, entertainment commodities, motor fuel, apparel services, housekeeping supplies, and gas and electricity.

Although we fail to find a significant, stochastic seasonal process in aggregate prices, a result that has been found elsewhere and for other macroeconomic data, we note that some of the component data exhibit significant stochastic variation at a seasonal frequency. This result may reveal those areas where the interaction between the seasonal and cyclical variation in prices is greatest. ${ }^{10}$ Obviously, more work in this potentially important area is advisable.

\section{Conclusion}

In this paper, we reevaluate the evidence of seasonality in prices in light of the substantial reduction in cyclical price movements that have allowed the seasonal patterns to become evident. We find the existence of seasonality to be substantially greater than previous research has indicated.

One central conclusion is drawn from this analysis. Seasonality in consumer prices is predominantly, although certainly not entirely, idiosyncratic in nature. This result stands in contrast to studies that demonstrate a common seasonal cycle in real economic variables, such as industrial production and retail sales. Furthermore, given the statistical criteria that the BLS uses to selectively seasonally adjust component data, the existence of

\footnotetext{
${ }^{10}$ See, for example, Miron (1990) and Cecchetti, Kashyap, and Wilcox (1994).
} 
unadjusted data in the index may inadvertently allow noise to be incorporated into the price index at the seasonal frequency. This implication argues in favor of seasonally adjusting the index after aggregation. 


\section{References}

Barsky, Robert B. and Jeffrey A. Miron. "The Seasonal Cycle and the Business Cycle," Journal of Political Economy, vol. 97, no. 3 (1989), pp. 503-34.

Beaulieu, J. Joseph, and Jeffrey A. Miron, "Seasonality in U.S. Manufacturing," NBER Working Paper No. 3450, 1990.

Biehl, Andrew R., and John P. Judd, "Inflation, Interest Rates, and Seasonality," Federal Reserve Bank of San Francisco, Weekly Letter No. 93-35, October 15, 1993.

Bryan, Michael F., and Stephen G. Cecchetti, "Measuring Core Inflation," in Monetary Policy, N. Gregory Mankiw, ed., University of Chicago Press for NBER, 1994, pp. 195215.

Bureau of Labor Statistics, BLS Handbook of Methods, Bulletin 2285. Chapter 19, "The Consumer Price Index."

Buszuwski, James A. and Claire Gallagher, "On the Use of Indirect Seasonal Adjustment Methods for the CPI," BLS Manuscript, June 1995.

Buszuwski, James A., and Stuart Scott, "On the Use of Intervention Analysis in Seasonal Adjustment," Proceedings of the American Statistical Association Section on Business and Economic Statistics (1988).

Cecchetti, Stephen G., Anil K. Kashyap, and David W. Wilcox, "Do Firms Smooth Seasonals in a Boom? Theory and Evidence," manuscript, 1994.

CPI Detailed Report, Bureau of Labor Statistics, January, 1994, pp. 11-15.

Federal Reserve Bulletin, Minutes of the Federal Open Market Committee Meeting of May 18, 1993, July 1993, pg. 864.

Mankiw, N. Gregory and Jeffrey A. Miron, "Should the Fed Smooth Interest Rates? The Case of Seasonal Fluctuations," NBER Working Paper No. 3388, 1990.

Miron, Jeffrey A., “The Economics of Seasonal Cycles," NBER Working Paper No. 3522, 1990.

Newey, Whitney K., and Kenneth D. West, "A Simple, Positive Definite, Heteroskedasticity and Autocorrelation Consistent Covariance Matrix," Econometrica, vol. 55 (May 1987), pp. 703-08. 
FIGURE 1

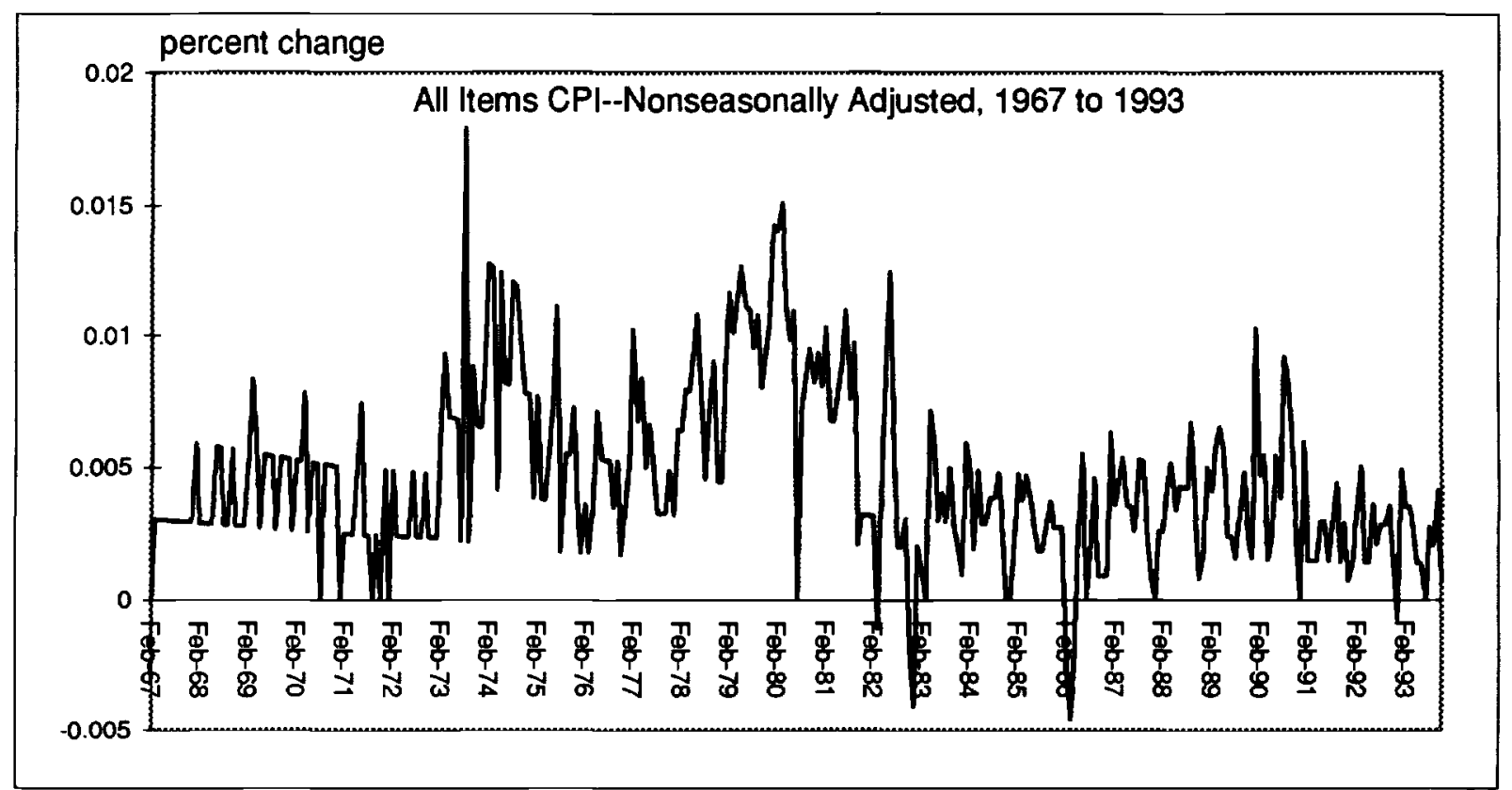

FIGURE 2

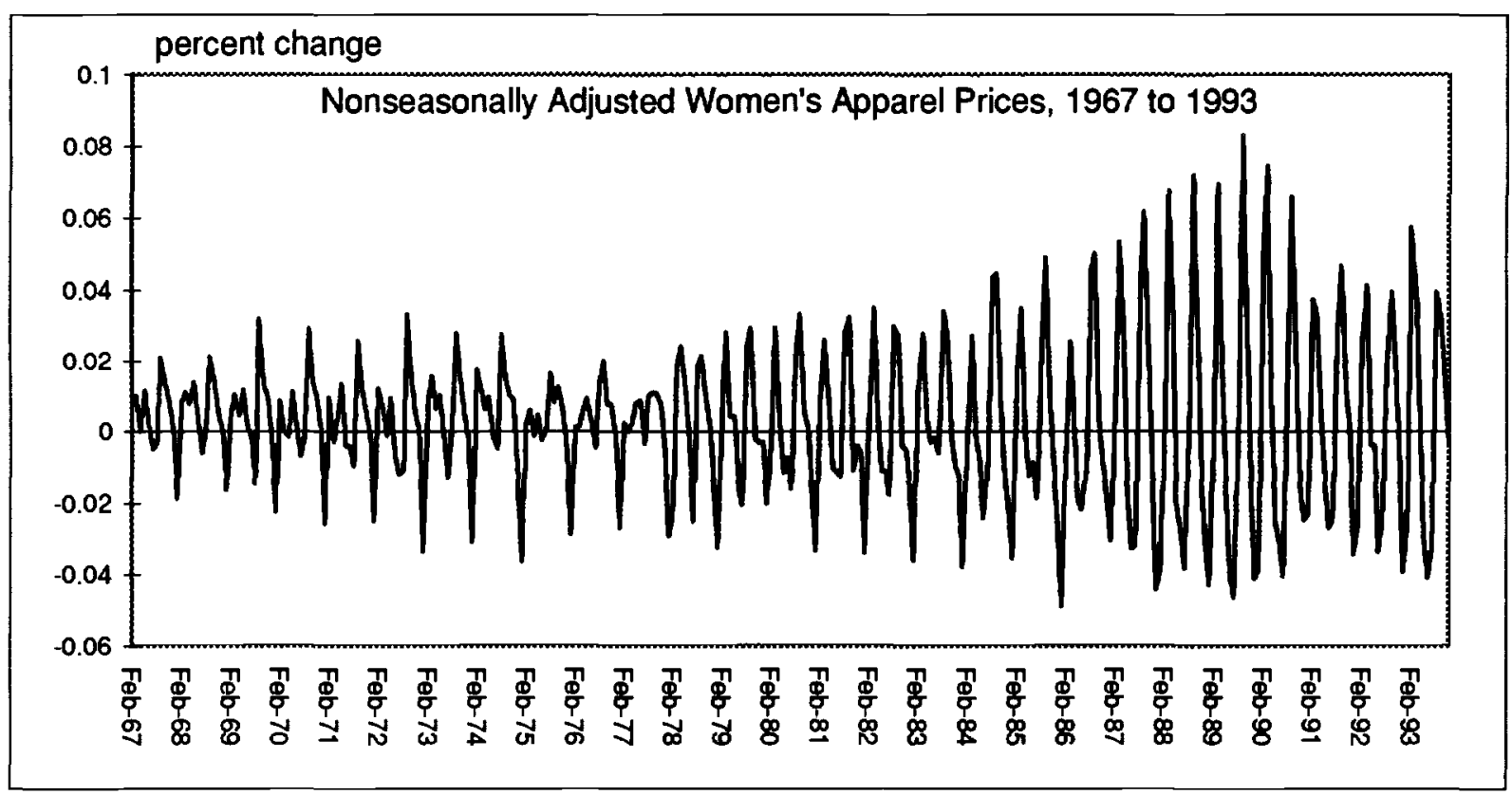


Table 1: Deterministic Seasonality in the CPI

(using Newey West correction)

\begin{tabular}{ccc}
\multicolumn{3}{c}{ Jan. $1967-$ Nov. 1993} \\
Jan & $\alpha$, & t-stat \\
Feb & 0.054 & 1.50 \\
Mar & 0.002 & 0.09 \\
Apr & 0.102 & 0.27 \\
May & 0.029 & 0.88 \\
Jun & 0.018 & 0.56 \\
Jul & 0.067 & 2.53 \\
Aug & -0.053 & -1.46 \\
Sep & -0.006 & -0.19 \\
Oct & 0.121 & 3.00 \\
Nov & 0.024 & 0.80 \\
Dec & -0.100 & -3.09 \\
& -0.165 & -4.00 \\
R2 & 0.068 & \\
Wald & 88.040 & \\
p-value & 0.000 &
\end{tabular}

$\begin{array}{ccc}\text { Jan. } 1967-\text { Dec. } 1981 \\ & \alpha & \text { t-stat } \\ \text { Jan } & -0.009 & -0.27 \\ \text { Feb } & 0.011 & 0.29 \\ \text { Mar } & 0.019 & 0.39 \\ \text { Apr } & 0.014 & 0.33 \\ \text { May } & 0.014 & 0.38 \\ \text { Jun } & 0.077 & 3.21 \\ \text { Jul } & -0.052 & -0.89 \\ \text { Aug } & -0.058 & -1.31 \\ \text { Sep } & 0.074 & 1.34 \\ \text { Oct } & 0.039 & 0.76 \\ \text { Nov } & -0.038 & -1.09 \\ \text { Dec } & -0.091 & -1.98 \\ & & \\ \text { R2 } & 0.032 & \\ \text { Wald } & 44.650 & \\ \text { p-value } & 0.000 & \end{array}$

Jan. 1982 - Nov. 1993

$\alpha$, t-stat

Jan $0.139 \quad 2.80$

Feb $\quad-0.007 \quad-0.25$

$\begin{array}{lll}\text { Mar } \quad 0.000 & 0.01\end{array}$

$\begin{array}{lll}\text { Apr } & 0.050 \quad 0.92\end{array}$

May $\quad 0.024 \quad 0.47$

Jun $\quad 0.055 \quad 1.12$

Jul $\quad-0.054 \quad-1.83$

Aug $\quad 0.059 \quad 1.75$

$\begin{array}{lll}\text { Sep } & 0.181 & 4.21\end{array}$

Oct $0.007 \quad 0.29$

Nov $\quad-0.176 \quad-4.53$

Dec $\quad-0.278 \quad-6.53$

R2 $\quad 0.320$

Wald 330.600

p-value 0.000 
Table 2: Deterministic Seasonality in 36 CPI Components $1982-1993$

(using Newey West correction, variances reported scaled by 10,000)

CPI

Food away from home

Auto repair

Apparel services

Personal services

Housekeeping services

Medical commodities

Entertainment commodities

Housekeeping supplies

Toilet goods

Cereals

Shelter

Entertainment services

Other trans. commodities

Medical services

Dairy

Other utilities

Household furnishings

Alcoholic beverages

Other food

Public transportation

Meats

Other trans. services

New vehicles

Used vehicles

Tobacco

Other apparel

Infants' apparel

Books and supplies

Footwear

Educational services

Men's apparel

Motor fuel

Fruits

Gas and electricity

Fuel oil

Women's apparel
Unconditional $\quad$ R2

$\begin{array}{ccc}\text { Seasonal } & \text { Unconditional } & R 2 \\ 0.01406 & 0.04394 & 0.32\end{array}$

0.00165

0.01868

0.09

0.00616

0.04310

0.14

0.00773

0.06910

0.11

0.00952

0.01233

0.06754

0.14

0.14055

0.09

0.01643

0.02178

0.06702

0.25

0.10541

0.21

0.02290

0.13655

0.17

0.02549

0.19028

0.13

0.09709

0.28

0.02785

0.12018

0.23

0.02902

0.09736

0.30

0.03478

0.28866

0.12

0.03849

0.06792

0.57

0.03989

0.28452

0.14

0.04266

0.26639

0.16

0.04366

0.16937

0.26

0.30373

0.21

0.20477

0.61

0.12482

1.12806

0.11

0.76826

0.17

0.27041

0.51

0.13856

0.24708

0.65

0.27306

0.87139

0.31

0.32535

0.47608

1.27310

0.26

1.79247

0.27

0.68437

2.94988

0.23

0.76361

1.01300

0.75

0.83807

1.08842

1.30880

1.78895

1.79705

2.15611

2.71104

7.70884

1.22939

0.68

1.37163

0.79

1.58662

0.82

10.13414

0.18

6.02819

0.30

2.78571

0.77

14.95497

0.18

9.40582

0.82 
Table 3: Deferministic Seasonality in Individual CPI Components (1982-1993)

(std. errors below, results use Newey West procedure)

Boldface type indicates statistical confidence at the $99 \%$ level

Name
CPI

Cereals

Meats

Dairy

Fruits

Other food

Food away from home

Alcoholic beverages

Shelter

Fuel oil

Gas and electricity

Other utilities

Household furnishings

Housekeeping supplies

Housekeeping services

Men's apparel

Women's apparel

Infants' apparel

Other apparel
0.05

Feb Mar

$0.00 \quad 0.05$

0.03

0.05

0.05

May

0.02

0.09

$0.02 \quad-0.16$

$0.13-0.02$

0.05

0.07

0.05

\section{$-0.36-0.40$}

0.2

0.22

0.2

0.79

0.29

0.13

$-0.03$

0.23

0,3

$-0.30$

$\begin{array}{llll}-0.34 & -0.24 & -0.12 & 0.07\end{array}$

$\begin{array}{llll}0.17 & 0.11 & 0.18 & 0.06\end{array}$

$\begin{array}{lllll}0.71 & 0.00 & -0.82 & -1.13 & -0.87\end{array}$

$0.48 \quad 0,48$

3.90
0.78

$0.51 \quad-0.58$

0.53

0.7

$-0.14 \quad-0.15$

$-0.1$

0.90

$0.46-0.12$

0.05

0.07

0.05

0.07

0.0

0.06

0.00

0.48

0.30

0.46

0.15

0.05

0.05

0.02

0.02

$\begin{array}{ll}0.12 & 0.01 \\ 0.07 & 0.06\end{array}$

0.1

0.09

0.00

0.01

$$
0.04
$$

0.10

$0.02 \quad 0.02$

$0.14 \quad 0.13$

$\begin{array}{rr}2.55 & -1.83 \\ 1.82 & 1.72\end{array}$

$-251$

$-1.56-0.87$

0.63

0.48

$-0.24 \quad-0.04$

$0.58 \quad-0.24$

$0.19 \quad 0.23$

0.18

$-0.38$

0.17

0.5

$-0.80$

0.08

$\begin{array}{ll}0.56 & 0.08 \\ 0.27 & 0.09\end{array}$

\section{$-0.02$}

$\begin{array}{lllll}0.02 & -0.05 & 0.05 & 0.03 & 0.06\end{array}$

0.10

0.1

0.32

0.00

0.11

0.23

0.12

0.10

$0.17-0.20$

$0.13 \quad 0.09$

0.09

0,0

\section{$-0.22$}

\subsection{0 .08}

$0.10 \quad 0.08$

$$
0.11
$$

0.08

$-0.05 \quad 0.28$

$0.06 \quad 0.21$

0.03

$0.15 \quad-0.07$

0.08

$0.20 \quad 0.05$

$\begin{array}{ll}-1.89 & -0.01\end{array}$

129

$0.70 \quad 0.16$

0.11

0.31

0.12

0.13

$4.20 \quad 0.64 \quad-1.67$

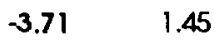

$0.23 \quad 0.68$

0.59

0.4

1.01

$0.46 \quad 0.82$

0.40

$0.97-0.31$

$0.54 \quad 0.28$

$-0.09$

$0.13-0.45$

$\begin{array}{ll}1.06 & 0.79 \\ 0.55 & 0.25\end{array}$

0.12

0.20

-0.45
0.13

-0.51
0.39

0.48
0.26

0.15
$0.06 \quad 0.11$

0.49

$\begin{array}{ccccc}\text { Sep } & \text { Oct } & \text { NoV } & \text { Dec } & R 2 \\ 0.18 & 0.01 & -0.18 & -0.28 & 0.32 \\ 0.04 & 0.03 & 0.04 & 0.04 & \end{array}$

$\begin{array}{lllll}-0.27 & -0.15 & -0.17 & 0.07 & 0.28\end{array}$

$\begin{array}{llll}0.06 & 0.03 & 0.06 & 0.06\end{array}$

$\begin{array}{llll}0.01 & -0.46 & -0.11 & 0.09\end{array}$

0.14

$\begin{array}{llll}0.16 & 0.23 & 0.06 & 0.08 \\ 0.11 & 0.13 & 0.09 & 0.12\end{array}$

$\begin{array}{llll}-0.79 & -0.92 & -0.62 & 0.61\end{array}$

0.30

0.61

$\begin{array}{llll}-0.13 & 0.19 & -0.48 & -0.24\end{array}$

0.07

0.09

0.21

$\begin{array}{lllll}-0.15 & -0.07 & 0.11 & -0.34 & -0.33\end{array}$

0.05

0.16

$\begin{array}{llllll}0.09 & 0.06 & 0.09 & 0.08 & 0.12\end{array}$

0.26

0.17

.09

0.83

82

$\begin{array}{lllllll}-2.71 & -2.72 & 2.54 & 4.78 & 1.18 & -1.02 & -2.97\end{array}$

$0.17 \quad 0.39$

0.82

0.23

0.27 
Table 3 (continued)

\begin{tabular}{|c|c|c|c|c|c|c|c|c|c|c|c|c|c|}
\hline 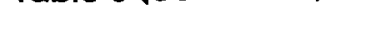 & Jan & Feb & Mar & Apr & May & Jun & Jul & Aug & Sep & Oct & Nov & Dec & $R 2$ \\
\hline \multirow{2}{*}{ Footwear } & -1.27 & 0.24 & 124 & 0.64 & 0.04 & -0.82 & -1.12 & -0.19 & 1.43 & 1.10 & -0.26 & -1.05 & 0.68 \\
\hline & 0.18 & 0.15 & 0.17 & 0.14 & 0.12 & 0.18 & 0.13 & 0.16 & 0.23 & 0.31 & 0.25 & 0.13 & \\
\hline \multirow[t]{2}{*}{ Apparel services } & 0.10 & 0.10 & 0.03 & $0 . \infty 0$ & 0.09 & -0.06 & -0.14 & -0.07 & -0.06 & 0.14 & $0 . \infty$ & -0.12 & 0.11 \\
\hline & 0.08 & 0.07 & 0.03 & 0.06 & 0.07 & 0.12 & 0.07 & 0.07 & 0.05 & 0.06 & 0.06 & 0.02 & \\
\hline \multirow[t]{2}{*}{ New vehicles } & 0.09 & -0.27 & -0.36 & -0.13 & -0.01 & -0.18 & -0.27 & -0.36 & -0.36 & 0.60 & 0.91 & 0.36 & 0.65 \\
\hline & 0.06 & 0.12 & 0.07 & 0.10 & 0.08 & 0.08 & 0.07 & 0.09 & 0.06 & 0.11 & 0.10 & 0.12 & \\
\hline \multirow[t]{2}{*}{ Used vehicles } & -0.92 & -0.79 & -0.20 & 0.54 & 0.82 & 0.65 & 0.27 & $0 . \infty$ & 0.03 & 0.13 & 0.00 & -0.52 & 0.31 \\
\hline & 0.26 & 0.26 & 0.17 & 0.16 & 0.21 & 0.24 & 0.21 & 0.14 & 0.11 & 0.08 & 0.10 & 0.17 & \\
\hline \multirow[t]{2}{*}{ Motor fuel } & -1.07 & -1.67 & -1.89 & 1.70 & 2.57 & 1.61 & -0.62 & 0.19 & 0.36 & 0.08 & -0.26 & -1.02 & 0.18 \\
\hline & 0.88 & 0.69 & 0.74 & 1.14 & 0.37 & 0.64 & 0.49 & 0.71 & 0.65 & 0.63 & 0.37 & 0.45 & \\
\hline \multirow[t]{2}{*}{ Auto repair } & $0 . \infty 0$ & 0.13 & 0.05 & $0 . \infty 0$ & -0.05 & -0.04 & -0.03 & -0.04 & 0.17 & 0.01 & -0.07 & -0.13 & 0.14 \\
\hline & 0.04 & 0.04 & 0.07 & 0.06 & 0.06 & 0.04 & 0.04 & 0.03 & 0.05 & 0.04 & 0.06 & 0.08 & \\
\hline \multirow[t]{2}{*}{ Other trans. commodities } & 0.10 & -0.07 & -0.29 & -0.10 & 0.11 & 0.02 & -0.29 & 0.19 & 0.05 & -0.20 & 0.30 & 0.19 & 0.12 \\
\hline & 0.23 & 0.10 & 0.13 & 0.14 & 0.14 & 0.13 & 0.13 & 0.12 & 0.09 & 0.11 & 0.16 & 0.07 & \\
\hline \multirow[t]{2}{*}{ Other trans. services } & 0.30 & -0.19 & -0.30 & -0.30 & -0.16 & 0.01 & 0.03 & -0.13 & -0.45 & 0.93 & 0.44 & -0.17 & 0.51 \\
\hline & 0.06 & 0.07 & 0.07 & 0.04 & 0.10 & 0.09 & 0.10 & 0.11 & 0.14 & 0.10 & 0.14 & 0.08 & \\
\hline \multirow[t]{2}{*}{ Public transportation } & 0.57 & -0.16 & -0.24 & -0.34 & -0.38 & -0.42 & 0.22 & -0.21 & -0.14 & 0.21 & 0.67 & 0.23 & 0.11 \\
\hline & 0.18 & 0.18 & 0.14 & 0.35 & 0.18 & 0.43 & 0.22 & 0.15 & 0.19 & 0.28 & 0.34 & 0.31 & \\
\hline \multirow{2}{*}{ Medical commodities } & -0.01 & 0.21 & 0.26 & 0.16 & 0.01 & -0.09 & -0.04 & -0.13 & -0.09 & -0.09 & -0.12 & -0.05 & 0.25 \\
\hline & 0.04 & 0.07 & 0.02 & 0.07 & 0.07 & 0.04 & 0.06 & 0.03 & 0.05 & 0.05 & 0.05 & 0.05 & \\
\hline \multirow[t]{2}{*}{ Medical services } & 0.38 & 0.31 & -0.05 & -0.17 & -0.19 & -0.12 & 0.19 & 0.05 & -0.16 & $0 . \infty$ & 0.03 & -0.26 & 0.57 \\
\hline & 0.03 & 0.03 & 0.06 & 0.04 & 0.04 & 0.03 & 0.03 & 0.04 & 0.03 & 0.03 & 0.05 & 0.03 & \\
\hline \multirow[t]{2}{*}{ Entertainment commodities } & 0.21 & 0.10 & 0.16 & 0.14 & -0.21 & -0.11 & 0.04 & -0.10 & -0.03 & 0.16 & -0.11 & -0.25 & 0.21 \\
\hline & 0.07 & 0.11 & 0.09 & 0.07 & 0.07 & 0.04 & 0.04 & 0.08 & 0.07 & 0.07 & 0.13 & 0.06 & \\
\hline \multirow[t]{2}{*}{ Entertainment services } & 0.23 & 0.04 & -0.14 & 0.15 & -0.27 & 0.08 & -0.04 & -0.06 & 0.26 & 0.14 & -0.17 & -0.22 & 0.30 \\
\hline & 0.10 & 0.05 & 0.06 & 0.05 & 0.06 & 0.08 & 0.07 & 0.06 & 0.11 & 0.07 & 0.07 & 0.07 & \\
\hline \multirow[t]{2}{*}{ Tobacco } & 134 & 0.05 & -0.34 & -0.37 & -0.20 & -0.07 & 0.89 & -0.53 & -0.72 & -0.14 & -0.24 & 0.33 & 0.26 \\
\hline & 0.30 & 0.13 & 0.13 & 0.14 & 0.20 & 0.26 & 0.27 & 0.23 & 0.41 & 0.25 & 0.17 & 0.28 & \\
\hline \multirow[t]{2}{*}{ Toilet goods } & 0.18 & 0.15 & 0.04 & 0.24 & -0.26 & -0.14 & 0.16 & -0.16 & -0.12 & $0 . \infty$ & 0.08 & -0.18 & 0.13 \\
\hline & 0.09 & 0.10 & 0.11 & 0.12 & 0.07 & 0.13 & 0.15 & 0.08 & 0.13 & 0.08 & 0.10 & 0.11 & \\
\hline \multirow[t]{2}{*}{ Personal services } & 0.17 & 0.10 & -0.18 & 0.03 & 0.04 & -0.06 & -0.17 & 0.01 & 0.07 & -0.04 & 0.01 & 0.01 & 0.14 \\
\hline & 0.06 & 0.05 & 0.09 & 0.05 & 0.08 & 0.05 & 0.07 & 0.05 & 0.06 & 0.04 & 0.07 & 0.05 & \\
\hline \multirow[t]{2}{*}{ Books and supplies } & 1.02 & 0.26 & -0.53 & -0.50 & -0.53 & -0.37 & -0.48 & -0.21 & 2.48 & -0.04 & -0.56 & -0.54 & 0.75 \\
\hline & 0.11 & 0.07 & 0.06 & 0.05 & 0.05 & 0.10 & 0.06 & 0.17 & 0.46 & 0.04 & 0.05 & 0.06 & \\
\hline \multirow[t]{3}{*}{ Educational services } & -0.21 & -0.37 & -0.37 & -0.39 & -0.42 & -0.42 & -0.31 & 0.15 & 3.38 & -0.02 & -0.52 & -0.50 & 0.79 \\
\hline & 0.09 & 0.07 & 0.05 & 0.04 & 0.07 & 0.07 & 0.05 & 0.22 & 0.58 & 0.11 & 0.04 & 0.05 & \\
\hline & Jan & Feb & Mar & Apr & May & Jun & Jul & Aug & Sep & Oct & Nov & Dec & \\
\hline number of significant $(+)$ & 12 & 7 & 5 & 4 & 3 & 2 & 3 & 2 & 6 & 6 & 3 & 2 & \\
\hline number of significant $(-)$ & 4 & 3 & 8 & 7 & 8 & 7 & 9 & 4 & 5 & 5 & 9 & 15 & \\
\hline total & 16 & 10 & 13 & 11 & 11 & 9 & 12 & 6 & 11 & 11 & 12 & 17 & \\
\hline
\end{tabular}


Table 4: Idiosyncratic Seasonality in 36 CPI Components 1982-1993

Auto repair

Food away from home

Entertainment services

Apparel services

Personal services

Housekeeping services

Entertainment commodities

Shelter

Other utilities

Medical commodities

Cereals

Toilet goods

Household furnishings

Housekeeping supplies

Medical services

Alcoholic beverages

Dairy

Other transportation commodities

Other food

Meats

Other transportation services

Public transportation

New vehicles

Used vehicles

Tobacco

Other apparel

Infants' apparel

Books and supplies

Footwear

Educational services

Men's apparel

Motor fuel

Fruits

Gas and electricity

Fuel oil

Women's apparel
VAR s(it) /

VAR S(t)

0.59917

0.76243

1.02518

1.11776

1.19945

1.36387

1.41811

1.75476

2.01226

2.02691

2.62600

2.64553

2.69258

2.89405

3.06386

3.22595

3.65126

4. 12955

7.05639

9.20606

11.97717

12.26934

16.25136

19.42488

25.24895

26.94287

45.54596

45.94267

55.30488

69.04402

88.35469

122.08662

124.72690

146.80739

192.29498

532.12456 
Table 5: Deterministic Seasonality in the Seasonally

Adjusted CPI: 1982-1993

(using Newey West correction)

$\begin{array}{ccc}\text { Pre-1994 Procedure } \\ \text { Jan } & \alpha & \\ \text { Feb } & 0.0016 & \text { t-stat } \\ \text { Mar } & -0.0003 & -0.21 \\ \text { Apr } & -0.0011 & -1.93 \\ \text { May } & 0.0004 & 0.60 \\ \text { Jun } & 0.0001 & 0.21 \\ \text { Jul } & 0.0003 & 0.41 \\ \text { Aug } & 0.0001 & 0.30 \\ \text { Sep } & -0.0003 & -0.88 \\ \text { Oct } & -0.0003 & -0.77 \\ \text { Nov } & -0.0008 & 2.35 \\ \text { Dec } & -0.0005 & -1.15 \\ & & -1.43 \\ \text { R2 } & 0.101 & \\ \text { Wald } & 44.470 & \\ \text { p-value } & 0.0000 & \end{array}$

\begin{tabular}{ccc}
\multicolumn{3}{c}{ Post-1993 Procedure } \\
& $\alpha$ & t-stat \\
Jan & 0.0008 & 1.71 \\
Feb & -0.0005 & -1.28 \\
Mar & -0.0008 & -1.31 \\
Apr & 0.0002 & 0.32 \\
May & 0.0002 & 0.39 \\
Jun & 0.0007 & 1.10 \\
Jul & 0.0001 & 0.26 \\
Aug & -0.0002 & -0.50 \\
Sep & -0.0002 & -0.53 \\
Oct & 0.0005 & 1.73 \\
Nov & -0.0002 & -0.54 \\
Dec & -0.0006 & -1.00 \\
& & \\
R2 & 0.053 & \\
Wald & 30.590 & \\
p-value & 0.0012 &
\end{tabular}


Table 6: Deterministic Seasonality in the Seasonally Adjusted CPI and the Seasonally Adjusted Median CPI (using Newey West correction, new procedure)

\begin{tabular}{ccccc} 
& \multicolumn{2}{c}{ CPI } & \multicolumn{3}{c}{ Median CPI } \\
& $\alpha$ & t-stat & $\alpha$, & t-stat \\
Jan & 0.0005 & 1.46 & 0.0003 & 1.27 \\
Feb & -0.0001 & -0.38 & -0.0002 & -0.86 \\
Mar & -0.0004 & -0.88 & -0.0005 & -1.72 \\
Apr & -0.0002 & -0.48 & 0.0001 & 0.43 \\
May & -0.0003 & -0.70 & -0.0002 & -0.56 \\
Jun & 0.0008 & 2.12 & 0.0004 & 1.26 \\
Jul & -0.0003 & -0.71 & 0.0000 & 0.02 \\
Aug & 0.0000 & 0.00 & 0.0004 & 1.45 \\
Sep & 0.0001 & 0.40 & -0.0002 & -0.66 \\
Oct & 0.0002 & 1.08 & 0.0002 & 0.49 \\
Nov & 0.0000 & 0.02 & 0.0000 & -0.17 \\
Dec & -0.0003 & -0.81 & 0.0000 & -0.53 \\
& & & & \\
R2 & 0.010 & & 0.01 & \\
Wald & 24.820 & & 15.18 & \\
p-value & 0.0090 & & 0.174 &
\end{tabular}

\begin{tabular}{cccc} 
CPI & \multicolumn{3}{c}{ Median CPI } \\
$\alpha$ & t-stat & $\alpha$ & t-stat \\
0.0008 & 1.71 & 0.0004 & 1.45 \\
-0.0005 & -1.28 & -0.0001 & -0.3 \\
-0.0008 & -1.31 & 0.0001 & 0.22 \\
0.0002 & 0.32 & 0.0005 & 1 \\
0.0002 & 0.39 & -0.0003 & -0.64 \\
0.0007 & 1.10 & 0.0004 & 1.07 \\
0.0001 & 0.26 & 0.0001 & 0.23 \\
-0.0002 & -0.50 & 0.0000 & 0.28 \\
-0.0002 & -0.53 & -0.0006 & -1.59 \\
0.0005 & 1.73 & 0.0000 & -0.02 \\
-0.0002 & -0.54 & -0.0002 & -0.48 \\
-0.0006 & -1.00 & -0.0004 & -1.45 \\
& & & \\
0.05 & & 0.05 & \\
30.58 & & 31.97 & \\
0.0013 & & 0.0008 &
\end{tabular}


Table 7: Stochastic Seasonality in the CPI and Components 1982-1993

(using Newey West correction)

CPI

Cereals

Meats

Dairy

Fruits

Other food

Food away from home

Alcoholic beverages

Shelter

Fuel oil

Gas and electricity

Other utilities

Household furnishings

Housekeeping supplies

Housekeeping services

Men's apparel

Women's apparel

Infants' apparel

Other apparel

Footwear

Apparel services

New vehicles

Used vehicles

Motor fuel

Auto repair

Other trans. commodities

Other trans. services

Public transportation

Medical commodities

Medical services

Enter. commodities

Entertainment services

Tobacco

Toilet goods

Personal services

Books and supplies

Educational services

$\begin{array}{cr}\begin{array}{c}\text { without Deterministic } \\ \text { Wald }\end{array} & \text { p-value } \\ 0.412148 & 0.813773\end{array}$

19.6336

12.8219

1.5522

8.9438

43.4812

2.1967

7.0808

49.0183

2.2181

313.7587

2.8059

4.7049

28.1663

3.437

23.0618

13.5094

0.0967

26.0616

3.0012

10.963

7.6641

4.6747

1.0181

4.3387

3.6178

20.7485

1.4668

1.6251

123.717

4.4067

12.4474

0.2201

2.8849

2.6919

293.4063

100.668

\subsection{1}

0.0016

0.4602

0.0114

0

0.3334

0.029

0

0.3299

0

0.2459

0.0951

0

0.1793

0

0.0012

0.9528

0

0.223

0.0042

0.0217

0.0966

0.6011

0.1142

0.1638

0

0.4803

0.4437

0

0.1104

0.002

0.8958

0.2364

0.2603

0

0 with Deterministic

Wald p-value

$7.4942 \quad 0.0236$

\begin{tabular}{ll}
$5.642 \quad 0.0595$ \\
\hline .446 & 0.0657
\end{tabular}

\begin{tabular}{ll}
$5.4446 \quad 0.0657$ \\
\hline
\end{tabular}

$\begin{array}{ll}1.5523 & 0.4602\end{array}$

$\begin{array}{ll}1.8708 & 0.3924\end{array}$

$\begin{array}{ll}1.9228 & 0.3824\end{array}$

$0.5165 \quad 0.7724$

$3.7931 \quad 0.1501$

$\begin{array}{ll}5.2125 & 0.0738\end{array}$

$7.1812 \quad 0.0276$

$9.6267 \quad 0.0081$

$\begin{array}{ll}7.003 & 0.0302\end{array}$

$3.9263 \quad 0.1404$

$10.806 \quad 0.0045$

$6.0842 \quad 0.0477$

$7.7959 \quad 0.0203$

$\begin{array}{ll}6.331 & 0.0422\end{array}$

1.48330 .4763

$4.1555 \quad 0.1252$

$1.2125 \quad 0.5454$

$23.347 \quad 0$

$6.2327 \quad 0.0443$

$8.9065 \quad 0.0116$

$9.8272 \quad 0.0073$

$2.0889 \quad 0.3519$

$2.4884 \quad 0.2882$

$6.1998 \quad 0.0451$

$2.5277 \quad 0.2826$

8.25250 .0161

$2.1021 \quad 0.3496$

24.3490

$\begin{array}{lll}3.6727 & 0.1594\end{array}$

$9.4616 \quad 0.0088$

$5.8198 \quad 0.0545$

$4.5603 \quad 0.1023$

20.972

23.6430 